\title{
Laidunnuksen vaikutukset maitorotuisten sonnivasikoiden käyttäytymiseen ja hyvinvointiin luomunaudanlihantuotannossa
}

\author{
Paula Martiskainen ${ }^{1 *}$, Arto Huuskonen ${ }^{2)}$, Jaakko Mononen ${ }^{1)}$, Leena Tuomisto ${ }^{2)}$, Risto Kauppinen ${ }^{3)}$, \\ Janne Kiljala ${ }^{2)}$, Heli Lindeberg ${ }^{1)}$, Leena Ahola ${ }^{1)}$ ja Teppo Rekilä ${ }^{4}$ \\ ${ }^{1)}$ Kuopion yliopisto, Soveltavan biotekniikan instituutti, PL 1627, 70211 Kuopio, etuni- \\ mi.sukunimi@uku.fi,.pmartisk@hytti.uku.fi \\ ${ }^{2}$ MTT/Pohjois-Pohjanmaan tutkimusasema,92400Ruukki,etunimi.sukunimi@mtt.fi \\ ${ }^{3)}$ Pohjois-Savon ammattikorkeakoulu, Kotikyläntie 254,74100Iisalmi, risto.kauppinen@pspt.fi \\ ${ }^{4)}$ MTT/Turkistalous, Turkistie 8,69100Kannus, teppo.rekila@mtt.fi
}

\begin{abstract}
Johdanto
Luomukotieläintuotantoa ohjataan EU:n laatimalla ohjeistuksella, jonka mukaan laidunkaudella kaikkien nautojen tulee päästä päivittäin laitumelle (KTTK 2000). Sääntöä voidaan perustella eläinten hyvinvoinnilla. Laitumella nauta voi viettää lajityypillistä elämää, mihin kuuluu laiduntaminen, laumassa eläminen sekä vapaa liikkuminen. Perusteluja laidunnukselle voidaan hakea myös taloudesta. Rehukustannus muodostaa merkittävän osan naudanlihantuotannon muuttuvista kustannuksista, ja Suomen ilmasto-olosuhteissa halvimmat rehuyksiköt saadaan yleensä laitumelta. Lypsyrotuisia sonneja tai sonnivasikoita ei kuitenkaan ole Suomessa yleensä laidunnettu. Niiden kasvatus on tapahtunut sisätiloissa, joista eläimillä on ollut korkeintaan mahdollisuus mennä ulos jaloittelutarhaan. Eräänä syynä vähäiseen laidunnusintoon on lypsyrotuisten sonnien aktiivinen ja jossain määrin aggressiivinenkin luonne.

Selvitimme tutkimuksessamme laidunnuksen ja eri väkirehutasojen vaikutuksia sonnivasikoiden käyttäytymiseen ja hyvinvointiin.
\end{abstract}

\section{Aineisto ja menetelmät}

Laidunkoe suoritettiin MTT:n Pohjois-Pohjanmaan tutkimusasemalla kesällä 2003. Koe-eläimet, 27 ayrshire- ja friisiläisrotuista sonnivasikkaa, otettiin varhaisvälityksestä noin kahden viikon ikäisinä maalis-huhtikuun vaihteessa. Vasikoiden alkukasvatus tapahtui viiden vasikan ryhmäkarsinoissa lämpimässä navetassa. Vasikat saivat teollista juomarehua joko $61 \mathrm{~d}^{-1}, 81 \mathrm{~d}^{-1}$ tai vapaasti. Lisäksi vasikat saivat vapaasti väkirehua ja karkearehua. Vasikat nupoutettiin vajaan neljän viikon iässä. Eläimet siirrettiin osakuivikepohjaiseen kylmäpihattoon kahden kuukauden iässä toukokuun puolivälissä. Varsinainen laidunkoe alkoi 6.6. ja päättyi 7.10.

Vasikat blokitettiin elopainon mukaan kolmeen eri ryhmään, joista ne arvottiin eri koeryhmiin. Kontrollina toimi osakuivikepohjaisessa kylmäpihatossa kasvatettu Pihatto-ryhmä (9 vasikkaa). Laitumelle siirrettiin kaksi ryhmää, LaiMat (matala väkirehutaso, 8 vasikkaa) ja LaiKor (korkea väkirehutaso, 10 vasikkaa). Laidunryhmät laidunsivat kukin noin 0,5 ha peltolohkoilla (noin $500 \mathrm{~m}^{2} / \mathrm{eläin}$ ). Molemmilla laidunryhmillä oli käytössään kolmiseinäinen, oljella kuivitettu suojakatos ( $3 \mathrm{~m}^{2} / \mathrm{eläin)}$. Väkirehu tarjottiin kahdesta katetusta ruokintakaukalosta $(40$ x $200 \mathrm{~cm})$ ja molemmilla laitumilla oli siirrettävä vesisäiliö. Laidunnus toteutettiin lohkolaidunnuksena, jolloin eläimillä oli koko ajan tarjolla hyvälaatuista laidunrehua. Laitumet koostuivat monivuotisesta timotei-apilanurmesta sekä yksivuotisesta kaura-italianraiheinänurmesta. Lisäksi ryhmät saivat väkirehua joko $1,0 \mathrm{~kg}$ (LaiMat) tai $2,5 \mathrm{~kg}$ (LaiKor) eläintä kohden vuorokaudessa. Väkirehuna käytettiin litistettyä ohraa ja rypsiä, ja eläinten kivennäisten tarpeesta huolehdittiin.

Vasikat pidettiin pihatossa 4 × $8 \mathrm{~m}$ karsinassa, josta niillä oli pääsy 4 × $8 \mathrm{~m}$ hakepohjaiseen jaloittelutarhaan. Karsina oli jaettu puoliksi karsinan takaosassa sijaitsevaan oljella kuivitettuun makuualueeseen ja etuosassa sijaitsevaan betonipohjaiseen lantakäytävään. Eläintä kohden tilaa oli jaloittelutarha mukaan lukien 7,2 $\mathrm{m}^{2}$. Ruokintapöytä sijaitsi karsinan etuosassa, ja tilaa eläintä kohden oli n. 40 $\mathrm{cm}$. Karsinassa oli kaksi automaattista juomakuppia. Pihatto-ryhmän vasikat saivat nurmisäilörehua ja lisäksi väkirehua 2,5 kg eläintä kohden vuorokaudessa. Väkirehu oli sama kuin laidunryhmillä.

Laidunkauden aikana vasikat punnittiin neljän viikon välein, jolloin pystyttiin mittaamaan eläinten päiväkasvu.

Käyttäytymistarkkailu tehtiin heinäkuussa, jolloin eläimet olivat keskimäärin 4,5 kuukauden ikäisiä ja 147 kg painoisia. Sonnien käyttäytymistä havainnoitiin laidunryhmissä suoralla seurannalla 
ja pihattoryhmässä videoimalla käyttäen aikaviivevideonauhureita. Käyttäytymishavainnot kerättiin yhtä aikaa kaikilta ryhmiltä $6 \mathrm{~h}$ jaksoissa kolmen peräkkäisen vuorokauden aikana. Vuorokauden keskilämpötila oli tarkkailun aikana $19{ }^{\circ} \mathrm{C}$. Laidunryhmien tarkkailuun osallistui kaksi tarkkailijaa. Laidunvasikoiden havainnointi tehtiin tarkkailutorneista kolmen metrin korkeudelta kiikareita apuna käyttäen. Eläinyksilöt kyettiin erottamaan toisistaan. Suora tarkkailu laitumella oli mahdotonta pimeyden takia klo 0:00 - 2:20 välisen ajan, joten lopullisissa tuloksissa on käytetty $21,6 \mathrm{~h}$ ajalta kerättyjä käyttäytymistietoja. Vasikoiden käyttäytymistoiminnot ja sijainti kirjattiin 10 min välein ns. hetkellisen seurannan (instantaneous sampling) menetelmällä (Martin \& Bateson 1993). Sonnivasikoiden etogrammi koostui alun perin seitsemästäkymmenestä erilaisesta käyttäytymistoiminnosta, joita yhdistettiin laajemmiksi luokiksi, jotka liittyivät eläinten yleiseen aktiivisuuteen, syömiskäyttäytymiseen ja häiriökäyttäytymiseen.

Tilastollinen testaus suoritettiin SPSS-ohjelmalla (SPSS Inc., Chicago, IL, USA). Käyttäen eiparametristä usean riippumattoman otoksen testiä (Kruskal-Wallisin testi). Jos parametristen testien ehdot täyttyivät, käytettiin yksisuuntaista varianssianalyysiä (One-Way ANOVA) tai riippumattomien ryhmien t-testiä.

\section{Tulokset ja tulosten tarkastelu}

\section{Kasvu}

Vasikoiden päiväkasvu laskettiin 120 vuorokauden pituiselta laidunkaudelta. LaiMat-ryhmän eläimet kasvoivat keskimäärin $1230 \mathrm{~g} / \mathrm{vrk}$, LaiKor-ryhmän eläimet $1250 \mathrm{~g} / \mathrm{vrk}$ ja Pihatto-ryhmän eläimet 1160 g/vrk. Erot päiväkasvuissa laidunryhmien hyväksi johtuivat todennäköisesti siitä, että laitumella oli tarjolla jatkuvasti hyvälaatuista ruohoa.

Taulukko 1. Sonnivasikoiden käyttäytymisseurannan tulokset. Eri käyttäytymistoimintoihin kulutettu aika on esitetty prosentteina 21,6 tunnista.

\begin{tabular}{|c|c|c|c|c|}
\hline \multirow[t]{2}{*}{ Käyttäytymistoiminto } & \multicolumn{3}{|c|}{ Keskiarvo \pm keskihajonta (mediaani) } & \multirow{2}{*}{$\begin{array}{c}\text { Merkit- } \\
\text { sevyys }\end{array}$} \\
\hline & LaiMat & LaiKor & Pihatto & \\
\hline \multicolumn{5}{|l|}{ Yleinen aktiivisuus } \\
\hline liikkuu & $2,7 \pm 2,1 \quad(1,5)^{\mathrm{QR}}$ & $3,8 \pm 1,2 \quad(3,9)^{\mathrm{Q}}$ & $1,9 \pm 1,0 \quad(2,3)^{\mathrm{R}}$ & $*$ a \\
\hline seisoo & $45,7 \pm 1,9(45,0)^{Q}$ & $40,2 \pm 3,0(39,9)^{\mathrm{R}}$ & $38,0 \pm 5,8(39,2)^{R}$ & $* * \mathrm{a}$ \\
\hline makaa & $51,6 \pm 2,6(52,1)^{Q}$ & $56,1 \pm 2,1(55,9)^{R}$ & $60,1 \pm 5,9(58,5)^{R}$ & $* * \mathrm{a}$ \\
\hline nukkuu & $13,3 \pm 4,0(13,9)$ & $11,4 \pm 3,3(11,4)$ & $15,2 \pm 3,7(15,4)$ & $\mathrm{b}$ \\
\hline \multicolumn{5}{|l|}{ Syömiskäyttäytyminen } \\
\hline syö rehua & $1,7 \pm 0,4 \quad(1,5)^{\mathrm{Q}}$ & $1,6 \pm 0,4 \quad(1,5)^{\mathrm{Q}}$ & $15,0 \pm 2,7(14,6)^{\mathrm{R}}$ & $* * *$ a \\
\hline syö kuivikkeita & $0,0 \pm 0,0 \quad(0,0)^{Q}$ & $1,4 \pm 1,9 \quad(0,8)^{Q}$ & $0,0 \pm 0,0 \quad(0,0) \mathrm{Q}$ & $* * \mathrm{a}$ \\
\hline laiduntaa & $29,8 \pm 2,4(29,3)^{Q}$ & $17,9 \pm 2,6(17,5)^{\mathrm{R}}$ & - & $* * * \mathrm{c}$ \\
\hline syöminen yhteensä & $31,5 \pm 2,3(31,2)^{Q}$ & $20,9 \pm 2,1(21,0)^{R}$ & $15,0 \pm 2,7(14,6)^{\mathrm{S}}$ & $* * * \mathrm{~b}$ \\
\hline märehtii & $30,9 \pm 4,7(32,3)$ & $34,2 \pm 5,8(33,9)$ & $31,5 \pm 2,1(31,2)$ & a \\
\hline \multicolumn{5}{|l|}{ Häiriökäyttäytyminen } \\
\hline manipuloi rakenteita & $1,0 \pm 0,5 \quad(0,9)$ & $1,0 \pm 0,3 \quad(0,8)$ & $1,3 \pm 1,1 \quad(0,8)$ & a \\
\hline stereotypiat & $0,0 \pm 0,0 \quad(0,0)$ & $0,0 \pm 0,0 \quad(0,0)$ & $0,0 \pm 0,0 \quad(0,0)$ & a \\
\hline imee toista eläintä & $0,0 \pm 0,0 \quad(0,0)$ & $0,3 \pm 0,8 \quad(0,0)$ & $0,1 \pm 0,3 \quad(0,0)$ & a \\
\hline puskee aggressiivisesti & $0,0 \pm 0,0 \quad(0,0)^{\mathrm{Q}}$ & $0,2 \pm 0,3 \quad(0,0)^{\mathrm{Q}}$ & $0,6 \pm 0,6 \quad(0,8)^{\mathrm{Q}}$ & $*^{\mathrm{a}}$ \\
\hline
\end{tabular}

${ }_{\text {QRS }}$ Eri yläindeksi tarkoittaa, että ryhmien keskiarvojen välillä oli merkittävä $(\mathrm{p}<0.05)$ ero post hoc -testissä

${ }^{\mathrm{a}}$ Kruskal-Wallisin testi ${ }^{\mathrm{b}}$ One-Way ANOVA ${ }^{\mathrm{c}}$ riippumattomien ryhmien t-testi

\section{Yleinen aktiivisuus ja syömiskäyttäytyminen}

Taulukossa 1 on esitetty tulokset keskeisimpien käyttäytymistoimintojen osalta. Yleiseen aktiivisuuteen luokiteltiin kuuluvaksi liikkuminen, seisominen, makaaminen ja nukkuminen. Nukkumiseksi määriteltiin makuuasennot, joissa vasikka pystyi rentouttamaan niskansa. Kaikki ryhmät viettivät eniten aikaa makuulla, ja jonkin verran vähemmän aikaa seisaallaan. LaiMat-ryhmä käytti vähemmän aikaa makaamiseen ja enemmän aikaa seisomiseen kuin kaksi muuta ryhmää. Ero johtui todennäköisesti pidemmästä ajasta, jonka LaiMat-ryhmän eläimet käyttivät syömiskäyttäytymiseen ja nimen- 
omaan laiduntamiseen. LaiKor-ryhmän vasikat liikkuivat eniten. LaiMat-ryhmän ja Pihatto-ryhmän välillä ei ollut eroa liikkumiseen käytetyssä ajassa. Nukkumisajassa ei ollut eroja ryhmien välillä.

Syömiskäyttäytymiseen kuului rehun syöminen, kuivikkeiden syöminen, laiduntaminen ja märehtiminen. LaiMat-ryhmän vasikat käyttivät laiduntamiseen enemmän aikaa kuin LaiKor-ryhmän vasikat. Ero johtunee ryhmien saaman väkirehun määrästä, jolloin korkeamman väkirehutason ryhmän (LaiKor-ryhmä) ei ole tarvinnut hankkia lisäenergiaa laidunruohon muodossa yhtä paljon kuin matalamman väkirehutason ryhmän (LaiMat-ryhmä). Pihatto-ryhmän eläimet käyttivät enemmän aikaa tarjotun rehun (säilörehu ja väkirehu pihatossa, väkirehu laitumella) syömiseen kuin laidunryhmien eläimet. Kun kaikki syöminen (rehun, kuivikkeen ja laidunruohon) yhdistettiin, eniten syömiskäyttäytymiseen käyttivät aikaa LaiMat-ryhmän ja vähiten Pihatto-ryhmän vasikat. Tämä osoittaa, että riittävän rehumäärän hankkiminen laitumelta laiduntamalla vaatii enemmän aikaa kuin säilörehun syöminen ruokintapöydältä. Lisäksi pihatossa syöntiaikaa saattoi rajoittaa rehun saatavuus. Märehtimiseen käytetyssä ajassa ei ollut eroja ryhmien välillä. Säilörehu vaatii usein pidemmän märehtimisajan kuin laidunnettu ruoho (Phillips 1993). Pihatto-ryhmä on siten käyttänyt märehtimiseen yhtä paljon aikaa kuin laidunryhmät, vaikka rehun syöntiin käytetty aika on lyhyempi.

Karkearehun puutteen on havaittu lisäävän useiden suuhun liittyvien epänormaalien käyttäytymismuotojen esiintymistä naudoilla (Graf 1993). Tällaisia käyttäytymismuotoja ovat mm. kielenpyöritys ja rakenteiden manipuloiminen. Vaikka Pihatto-ryhmän vasikoiden syömisaika olikin lyhyempi kuin laidunryhmien eläinten, rakenteiden puremisessa ja nuolemisessa ei ollut eroja ryhmien välillä. Stereotyyppistä kielenpyöritystä ei havaittu missään ryhmässä. Toisaalta kaikkien ryhmien ruokinta oli karkearehuvaltaista. Vasikoiden juottokaudella ongelmaksi voi muodostua toisen eläimen ruumiinosien, kuten korvien, navan ja kivesten imeminen. Normaalisti käyttäytyminen kuitenkin häviää vieroituksen jälkeen (Jensen 2003). Toisen eläimen imeminen olikin erittäin harvinaista kaikissa ryhmissä: sitä tapahtui vain viidessä yhteensä 3510 eläinhavainnosta.

\section{Sosiaalinen käyttäytyminen}

Naudat ovat sosiaalisia eläimiä, jotka muodostavat arvojärjestyksen. Normaalisti naudat välttävät yhteenottoja dominanssihierarkiassa korkeammalla olevien eläinten kanssa väistämällä ja säilyttämällä itsensä ja muiden eläinten välissä yksilöetäisyyden. Tilan vähetessä dominoivan eläimen väistäminen vaikeutuu, mistä seuraa aggressiivisen käyttäytymisen lisääntyminen (Kondo ym. 1989). Aggressiot lisääntyvät myös ympäristön resurssien muuttuessa rajallisiksi, esim. ruokailutilan vähentämisen on havaittu lisäävän puskemista ja toisen eläimen häirintää aikuisten nautojen keskuudessa ruokintakaukalolla (Winckler 2000). Myös tässä kokeessa aggressiivista puskemista esiintyi lähinnä eläinten ollessa syömässä rehua tai juomassa, jolloin käytettävissä oleva tila oli rajoitettu. Pihatto-ryhmässä aggressiivista puskemista esiintyi vain hieman enemmän kuin laidunryhmissä, eikä tämä ero ollut tilastollisesti merkitsevä post hoc -vertailussa. Laitumellakin väkirehu tarjottiin ruokintakaukaloihin, joista eläimet söivät sen nopeasti. Tässä tilanteessa kooltaan pienemmät eläimet saattoivat olla suuria eläimiä huonommassa asemassa. Osaltaan aggressioiden vähäisyys kaikissa koeryhmissä voi johtua vasikoiden nuoresta iästä ( $4,5 \mathrm{kk})$, jolloin vasikkaryhmiin ei vielä välttämättä ollut muodostunut arvojärjestyksiä. Arvojärjestyksen muodostumisen ajankohdasta on esitetty useita toisistaan poikkeavia arvioita. Joissakin tutkimuksissa arvojärjestyksen täydellistä muodostumista ei ole havaittu miltei vuoden ikäisilläkään eläimillä (Reinhardt ym. 1978), kun taas toisilla eläimillä sen on todettu muodostuneen jo 1-2 kuukauden iässä (Albright \& Arave 1997).

\section{Eri alueiden käyttö laitumella ja pihatossa}

Käyttäytymistoimintojen lisäksi havainnoitiin myös vasikoiden sijainti, jolloin saatiin tietoa eri alueiden käytöstä laitumella ja pihatossa. Laidunalue oli jaettu kolmeen osaan: suojakatos ja sen välitön ympäristö, laitumen suojakatoksen puoleinen pää (jossa sijaitsivat ruokintakaukalot ja vesisäiliö) sekä laitumen suojakatoksesta kauimpana oleva pää. Laitumet eivät olleet toisiaan vastaavan muotoisia, joten suojakatoksen ympäristön alue oli huomattavasti suurempi LaiKor-ryhmän laitumella. Pihatto jaettiin makuualueeseen, lantakäytävään ja jaloittelutarhaan. Pihatto-ryhmä vietti ajastaan yhtä suuren osan makuualueella (36 \% ajasta) ja jaloittelutarhassa (36 \%). Vasikat käyttivät jaloittelutarhaa lepopaikkana aamu- ja iltapäivällä, ja illalla puskemisleikeissä ja muussa aktiivisuudessa. Lantakäytävää eläimet käyttivät $27 \%$ ajasta. Lantakäytävällä oleskelu liittyi suurelta osin rehun syömiseen. LaiMatryhmän eläimet viettivät suurimman osan ajastaan (47 \%) ruokintapaikan läheisyydessä, 29 \% suojakatoksessa ja sen ympäristössä ja $12 \%$ kauempana laitumella. LaiKor-ryhmässä vasikat oleskelivat 
eniten suojakatoksessa tai sen ympäristössä ( $80 \%$ ajasta), $13 \%$ ruokintapaikan ympäristössä ja $7 \%$ kauempana laitumella. Suosituimpia alueita käytettiin enimmäkseen lepäilyyn päivän aikana. Yöllä laidunryhmät oleskelivat suojakatoksessa ja pihattoryhmä makuualueella.

\section{Johtopäätökset}

Pihatossa vasikoiden käyttäytyminen on jonkin verran rajoitetumpaa kuin laitumella. Pihatossa ja laitumella pidettyjen eläinten välillä ei kuitenkaan ollut eroja epänormaalin käyttäytymisen määrässä ja ero aggressiivisessa käyttäytymisessäkin oli melko merkityksetön. Vasikat kasvoivat laitumella yhtä hyvin matalalla ja korkealla väkirehutasolla. Selkeitä hyvinvointieroja ryhmien välillä ei siis havaittu.

\section{Kirjallisuus}

Albright, J.L. \& Arave, C.W. 1997. The behaviour of cattle. CAB International. Wallingford, UK.

Graf, B. 1993. Abnormal oral behaviours in fattening bulls: incidence, causation and implications. Julkaisussa: Nichelmann, M., Wierenga, H.K. \& Braun, S. (toim.), Proceedings of the international congress on applied ethology, Berlin 1993. Sivut 47-52.

Jensen, M.B. 2003. The effects of feeding method, milk allowance and social factors on milk feeding behaviour and cross-sucking in group housed dairy calves. Appl. Anim. Behav. Sci. 80: 191-206.

Kondo, S., Sekine, J., Okubo, M. \& Asahida, Y. 1989. The effect of group size and space allowance on the agonistic and spacing behavior of cattle. Appl. Anim. Behav. Sci. 24: 127-135.

KTTK 2000. Luonnonmukaisen tuotannon ohjeet - eläintuotanto. KTTK:n julkaisuja 4/2000.

Martin, P. \& Bateson, P. 1993. Measuring behaviour. An introductory guide. Cambridge University Press. Cambridge.

Phillips, C.J.C. 1993. Cattle behaviour. Farming Press. London.

Reinhardt, V., Mutiso, F.M. \& Reinhardt, A. 1978: Social behaviour and social relationships between female and male prepubertal bovine calves (Bos indicus). Appl. Anim. Ethology 4: 43-54.

Ruckebusch, Y., Dougherty, R.W. \& Cook, H.M. 1974. Jaw movements and rumen motility as criteria for measurement of deep sleep in cattle. Am. J. Vet. Res. 10: 1309-1312.

Winckler, C. 2000. Effects of feeding and manger space allowance on feeding behaviour and agonistic interactions in dairy cattle. Julkaisussa: Ramos, A., Pinheiro Machado Filho, L.C. \& Hötzel, M.J. (toim.), Proceedings of the $34^{\text {th }}$ International Congress of the ISAE, Florianapólis, Brazil. Sivu 214. 